\title{
D-dimer Level is Correlated with Prognosis, Infarct Size, and NIHSS in Acute Ischemic Stroke Patients*
}

\author{
Nora I Abbas ${ }^{1} \odot$, Osama Sayed ${ }^{2}$, Sherif Samir ${ }^{3}$, Nashwa Abeed ${ }^{4}$
}

\begin{abstract}
Stroke ranks the fourth leading disease causing adult mortality and disability. D-dimer (D-D) is the ultimate product of plasmin-mediated degradation of fibrin-rich thrombi. D-D is a simple readily accessible biomarker employed within the diagnostic algorithms for the exclusion of venous thromboembolism. The correlation between D-D infarct size in MRI brain, APACHE II score, and the National Institute of Health Stroke Scale (NIHSS) score in critically ill acute stroke patients has not been fully investigated before.

Objective: We aimed to investigate the diagnostic and prognostic value of elevated plasma D-D in critically ill patients admitted with acute cerebrovascular accidents. As far as we know, we are the first to investigate the correlation between plasma D-D levels and the ischemic lesion size in MRI brain and also APACHE II score and NIHSS in critically ill acute ischemic cerebrovascular patients.

Setting and participants: A prospective, observational cohort study inside the Critical Care Medicine Department. Thirty patients with AIS were enrolled additionally to 1 healthy age- and sex-matched controls.

Interventions: We employed particle-enhanced, immunoturbidimetric assay to detect plasma D-D concentrations. D-D levels D0 and D1 were measured upon admission and 24 hours later, respectively. We reviewed the patient's health records; additionally, demographic, clinical, laboratory, and neuroimaging information was abstracted.

Results: D-D concentrations were significantly higher in acute stroke patients compared to healthy controls. ROC curve analysis showed that elevated D-D level more than $310 \mathrm{ng} / \mathrm{mL}$ can predict infarct lesion size $>1.5 \mathrm{~cm}$ in diffusion-weighted MRI brain with sensitivity and specificity (100 and $83 \%$, respectively) and also admission D-D (D0) at cutoff concentration $350 \mathrm{ng} / \mathrm{mL}$ and D1 at cutoff value $370 \mathrm{ng} / \mathrm{mL}$ are predictors of complicated course with sensitivity and specificity (100 and $84.6 \%$, respectively). There was no significant difference between D0 and D1 D-D levels ( $p$-value $>0.05$ ).

Conclusion: The plasma D-D biomarker can be a simple readily available test reliable predictor of infarct lesion size $>1.5 \mathrm{~cm}$ in DW-MRI and outcome in union with the common practice instrumental tests.

Keywords: Acute ischemic stroke, APACHE II, D-dimer levels, MRI infarction size, NIHSS, Prognosis.

Indian Journal of Critical Care Medicine (2021): 10.5005/jp-journals-10071-23744
\end{abstract}

*The abstract was accepted as e-poster in the Emirates Critical Care Conference (ECCC) held in 2019 April in Dubai. All accepted neurocritical abstracts were published in the Neurocritical Care journal.

\section{INTRODUCTION}

Stroke ranks the fourth leading health problem causing adult mortality and disability. ${ }^{1}$

Rapid diagnosis in patients with suspected acute stroke is crucial for the timely suitable management. Radiological confirmation of the diagnosis is often delayed because computed tomography (CT) may be normal in the early stages or in patients with insignificant clinical picture and magnetic resonance imaging (MRI) is not always accessible within the golden hours of treatment. Thus, many eligible cases are delayed in receiving thrombolytic therapy. ${ }^{2}$

D-dimer (D-D), the ultimate product of plasmin-mediated degradation of fibrin-rich thrombi, has emerged as a simple blood test that can be employed in diagnostic algorithms for the exclusion of venous thromboembolism. ${ }^{3}$

Many researchers concluded that elevated D-D levels occur during the acute phase of stroke, which eventually decrease. ${ }^{4,5}$

Elevated D-D concentrations are found to be prognostic of long-term neurologic outcomes in childhood-onset arterial ischemic stroke. $^{6}$

\footnotetext{
${ }^{1,4}$ Critical Care Medicine Department, Faculty of Medicine, Cairo University, Cairo, Egypt

${ }^{2}$ Critical Care Department, Nasser Institute for Research, Cairo, Egypt

${ }^{3}$ Critical Care Medicine Department, Faculty of Medicine, Beni Suef University, Cairo, Egypt

Corresponding Author: Nora I Abbas, Critical Care Medicine Department, Faculty of Medicine Department, Cairo University, Cairo, Egypt, Phone: +20 25257259, e-mail: narnar_77@yahoo.com
}

How to cite this article: Abbas NI, Sayed O, Samir S, Abeed N. D-dimer Level is Correlated with Prognosis, Infarct Size, and NIHSS in Acute Ischemic Stroke Patients. Indian J Crit Care Med 2021;25(2):193-198.

Source of support: Nil

Conflict of interest: None

Elevated D-D level has also been shown to relate to early clinical progression, ${ }^{7}$ infarction volume, ${ }^{4}$ unfavorable outcome ${ }^{8}$ in AIS patients, and poor functional outcome after acute spontaneous intracerebral hemorrhage. ${ }^{9}$

\footnotetext{
(c) Jaypee Brothers Medical Publishers. 2021 Open Access This article is distributed under the terms of the Creative Commons Attribution 4.0 International License (https://creativecommons.org/licenses/by-nc/4.0/), which permits unrestricted use, distribution, and non-commercial reproduction in any medium, provided you give appropriate credit to the original author(s) and the source, provide a link to the Creative Commons license, and indicate if changes were made. The Creative Commons Public Domain Dedication waiver (http://creativecommons.org/publicdomain/zero/1.0/) applies to the data made available in this article, unless otherwise stated.
} 


\section{Subjects And Methods}

\section{Study Design and Patient Selection}

It is a prospective non-interventional cohort study conducted on 40 subjects divided into 30 patients with first-ever ischemic stroke admitted within 24 hours of the onset of symptoms at ICU, and 10 age- and sex-matched healthy controls. All patients were fulfilling the inclusion criteria in the absence of any exclusion criteria.

Our study was conducted on 40 persons divided into two groups as follows:

\section{1-Patient group:}

It included 30 patients with first-ever ischemic stroke admitted to the Critical Care Department during 6 months duration. Their age ranged between 25 and 63 years with a mean of $52.367 \pm 8.438$; they were 10 men (33.33\%) and 20 women (66.67\%).

\section{2-Control group:}

It included 10 healthy subjects matched with age (ranged $40-60$ years) with a mean $(52 \pm 6.394)$ and sex; they were five men (50\%) and five women (50\%) without family history of stroke or coagulopathy.

\section{The patients were fulfilling the following inclusion criteria:}

Inclusion criteria: Patients older than 18 years old with acute ischemic stroke admitted to the ICU within 24 hours of onset of symptoms.

Exclusion criteria: Age older than 70 years because D-D increases with age. ${ }^{10}$ Hemorrhagic stroke; delay over 24 hours from symptom onset to admission; and patients receiving anticoagulants before admission are also excluded. Patients with conditions known to affect coagulation, like sepsis, malignancy, acute venous thromboembolism, hypercoagulable state, collagen diseases, recent surgery, and/or trauma within 30 days and acute cardiac infarction within 10 days. $^{11}$

Epileptic seizure activity before admission ${ }^{12}$; severe coma or terminal illness and disease with the potentiality of false-positive D-D, e.g., liver diseases; and trauma are also among the exclusion criteria list.

\section{Clinical Variables}

All patients were subjected to full neurological and general medical history and examination. The National Institute of Health Stroke Scale (NIHSS) score at admission was employed to classify stroke severity as follows: 0 to $7=$ mild case regarding severity and good outcome; 8 to 12 = moderate severity and bad outcome; and a score of 13 or more $=$ severe case. ${ }^{13}$ Laboratory investigations included routine laboratory investigations (CBC, blood sugar, liver and renal function tests, and lipid profile) additionally to plasma (D-D) concentration upon admission [Day 0] and 24 hours later [Day 1]. Blood samples were withdrawn prior to the initiation of any oral, enteral, or parenteral feeding or medications.

Radiological investigations included computed tomography (CT) brain and MRI brain with diffusion within 24 hours of neurological deficit onset.

Cortical or cerebellar lesions and brain stem or subcortical hemispheric infarcts greater than $1.5 \mathrm{~cm}$ in diameter have the potential of large artery atherosclerotic origin. ${ }^{14}$

Electrocardiography (ECG); transthoracic echocardiography (TTE); and carotid and vertebrobasilar duplex were also performed.

\section{Blood Collection and Test}

Blood sample ( $9 \mathrm{vol}$.) is collected on $0.109 \mathrm{M}$ citrate anticoagulant (1 vol.) by aseptic venipuncture; plasma supernatant is decanted for subsequent 20 minutes. Blood samples were centrifuged twice at $2500 \mathrm{rpm}$ immediately after admission. The plasma was snap-frozen and stored at $-20^{\circ} \mathrm{C}$ and defrosted for 15 minutes immediately before use at $37^{\circ} \mathrm{C}$. The sample experienced 50 -fold (1:50) weakened within the sample diluent.

The laboratory technicians responsible for D-D level analysis in the blood samples are blind to the diagnosis of patient group and control group. D-D concentrations are measured by means of a D-D assay ELISA kits (ZYMUTEST D-Dimer ARK023A) with a reference level (0-250 ng/mL D-D units \{DDUs\}).

\section{Statistical Analysis}

Data were coded and entered by means of the statistical package SPSS version 22.

Mean and variance for quantitative variables and frequencies (cases' number) and relative frequencies (percentages) for categorical variables were employed for data summarization. Unpaired $t$ test was employed for comparisons between groups.

Comparison between D-D measured at time of admission D0 and D1 D-D was done using paired $t$ test.

For comparing categorical data, Chi-square $\left(\chi^{2}\right)$ test was performed. Exact test was used instead when the expected frequency is less than 5 . Correlations between variables were done using the Pearson parametric statistic. The receiver operating characteristic (ROC) curve analysis was used to determine appropriate D-D cutoff point for a positive infarction diameter greater than $1.5 \mathrm{~cm}$ in MRI brain as well as prediction of complicated outcome. Continuous data were expressed as mean standard deviation. $p<0.05$ was considered as statistically significant.

\section{Results}

Ten males (33.3\%) and twenty females (66.7\%) constitute the patient group. The mean \pm SD age of the patients was $52.37 \pm 8.44$ years (ranged from 25 to 63 years).

MRI brain results showed cerebral infarct size greater than $1.5 \mathrm{~cm}$ in $60 \%$ of patients, while ischemic infarct size less than $1.5 \mathrm{~cm}$ was found in $40 \%$ of patients.

Comparison of mean value of D0 and D1 D-D between patients with or without risk factors of ischemic stroke like smoking, alcohol abuse, HTN, DM, and dyslipidemia showed no significant difference. The mean of DO D-D is $480 \pm 87.14 \mathrm{ng} / \mathrm{mL}$ in patients with AF and $333.45 \pm 98.16 \mathrm{ng} / \mathrm{mL}$ in patients with no AF. The mean of D1 D-D is $506.25 \pm 82.1 \mathrm{ng} / \mathrm{mL}$ in patients with $\mathrm{AF}$ and $337.5 \pm 113.67 \mathrm{ng} / \mathrm{mL}$ in patients with no AF. There was statistical significance between patients with and without AF as regards D0 and D1 D-D levels $(p<0.05)$ (Table 1).

The mean of D0 was $444.18 \pm 109.24 \mathrm{ng} / \mathrm{mL}$ in patients with coronary heart diseases (CHD) and $331.05 \pm 98.03 \mathrm{ng} / \mathrm{mL}$ in patients with no CHD. The mean of D1 D-D was $470.91 \pm 112.11 \mathrm{ng} / \mathrm{mL}$ in patients with IHD and $331.32 \pm 111.59 \mathrm{ng} / \mathrm{mL}$ in patients without IHD. There was statistical significance between patients with and without CHD as regards D0 and D1 D-D levels $(p<0.05)$ (Table 1$)$.

There was difference showing statistical significance of early time of admission (within 12 hours of symptom onset) as regards of D0 and D1 D-D levels ( $p<0.05$ ) (Table 2).

There was a statistically significant difference of finding in MRI as regards D0 and D1 D-D levels $(p<0.05)$ (Table 3$)$. 
D-dimer Levels as Predictor of Stroke Prognosis

Table 1: Comparison between ischemic stroke patients with and without cardiovascular risk factors

\begin{tabular}{|c|c|c|c|c|c|}
\hline & & DO D-dimer $($ mean $\pm S D) \mathrm{ng} / \mathrm{mL}$ & D1 D-dimer (mean $\pm S D) n g / m L$ & Dop value & D1 $p$ value \\
\hline \multirow[t]{2}{*}{ Smoker } & Yes & $347.36 \pm 85.93$ & $360.45 \pm 107.81$ & 0.370 & 0.487 \\
\hline & No & $387.11 \pm 128.37$ & $395.26 \pm 141.60$ & & \\
\hline Alcohol abuse & No & $372.53 \pm 114.69$ & $382.50 \pm 129.40$ & & \\
\hline \multirow[t]{2}{*}{ HTN } & Positive & $393.23 \pm 112.11$ & $108.64 \pm 119.43$ & 0.102 & 0.065 \\
\hline & Negative & $315.62 \pm 108.35$ & $310.62 \pm 136.13$ & & \\
\hline \multirow[t]{2}{*}{ DM } & Positive & $377.08 \pm 94.42$ & $384.17 \pm 113.75$ & 0.863 & 0.955 \\
\hline & Negative & $369.50 \pm 129.02$ & $381.39 \pm 142.08$ & & \\
\hline \multirow[t]{2}{*}{ Dyslipidemia } & Positive & $359.58 \pm 89.61$ & $360.00 \pm 108.90$ & 0.622 & 0.446 \\
\hline & Negative & $381.17 \pm 130.56$ & $397.50 \pm 142.46$ & & \\
\hline \multirow[t]{2}{*}{$\mathrm{AF}$} & Positive & $480.00 \pm 87.14$ & $506.25 \pm 82.10$ & 0.001 & $<0.001$ \\
\hline & Negative & $333.45 \pm 98.16$ & $337.50 \pm 113.67$ & & \\
\hline \multirow[t]{2}{*}{ IHD } & Positive & $444.18 \pm 109.24$ & $470.91 \pm 112.11$ & 0.007 & 0.003 \\
\hline & Negative & $331.05 \pm 98.03$ & $331.32 \pm 111.59$ & & \\
\hline
\end{tabular}

HTN, hypertension; DM, diabetes mellitus; AF, atrial fibrillation; IHD, ischemic heart disease

Table 2: Time of admission and D0 (admission) and D1 (after 24 hours) D-dimer

\begin{tabular}{|c|c|c|}
\hline & $\begin{array}{l}\text { DO D-dimer } \\
(\text { mean } \pm S D) n g / m L\end{array}$ & $\begin{array}{l}\text { D1 D-dimer } \\
(\text { mean } \pm S D) n g / m L\end{array}$ \\
\hline Early $12 \mathrm{hrs}$ & $338.55 \pm 117.86$ & $344.75 \pm 127.46$ \\
\hline Late $12-24 \mathrm{hrs}$ & $440.50 \pm 73.20$ & $458.00 \pm 100.78$ \\
\hline$p$ & 0.007 & 0.015 \\
\hline
\end{tabular}

${ }^{*} p$ value is of statistical significance if $<0.05$

Table 3: Comparison between size of infarction in MRI and D0 (admission) and D1 (after 24 hours) D-dimer

\begin{tabular}{lll}
\hline & $\begin{array}{l}\text { Do D-dimer } n g / m L \\
(\text { mean } \pm S D)\end{array}$ & $\begin{array}{l}\text { D1 D-dimer } n g / m L \\
(\text { mean } \pm S D)\end{array}$ \\
\hline Positive $>1.5 \mathrm{~cm}$ & $450.00 \pm 63.18$ & $475.56 \pm 61.97$ \\
Positive $<1.5 \mathrm{~cm}$ & $256.33 \pm 62.93$ & $242.92 \pm 52.76$ \\
$p$ & $<0.001$ & $<0.001$ \\
\hline
\end{tabular}

${ }^{*} p$ value is significant if $<0.05$

The relation between D0 and D1 D-D and prognosis (pneumonia and/or mortality) patients shows that the mean of D0 $D$ - $D$ is $262.00 \pm 63.62 \mathrm{ng} / \mathrm{mL}$ among non-complicated patients and $457.06 \pm 57.34 \mathrm{ng} / \mathrm{mL}$ among complicated patients. The mean of D1 D-D is $249.62 \pm 55.99 \mathrm{ng} / \mathrm{mL}$ among non-complicated patients and $484.12 \pm 51.76 \mathrm{ng} / \mathrm{mL}$ among complicated patients ( $p$-value $<0.05$ ) (Table 4).

D0 D-D with cutoff concentration $310 \mathrm{ng} / \mathrm{mL}$ and D1 with cutoff concentration $295 \mathrm{ng} / \mathrm{mL}$ are predictors of MRI stroke size equal to or greater than $1.5 \mathrm{~cm}$ with $100 \%$ sensitivity and $83.3 \%$ specificity (Fig. 1, Table 5).

D0 D-D with cutoff level $350 \mathrm{ng} / \mathrm{mL}$ and D1 with cutoff level $370 \mathrm{ng} / \mathrm{mL}$ can predict mortality and poor outcome with sensitivity and specificity (100 and $84.6 \%$, respectively) (Fig. 2, Table 6).

There was a statistically significant correlation between D0 and D1 D-D and APACHE II score and NIHSS ( $p$-value <0.05) (Table 7).
Table 4: Sensitivity and specificity of D0 (admission) D-dimer and D1 (after 24 hours) D-dimer for predicting infarct size greater than $1.5 \mathrm{~cm}$ in MRI brain

\begin{tabular}{llllll}
\hline $\begin{array}{l}\text { MRI infarct size } \\
>1.5 \mathrm{~cm}\end{array}$ & AUC & $p$ & Cutoff & Sensitivity & Specificity \\
\hline D0 D-dimer $\mathrm{ng} / \mathrm{mL}$ & $92.1 \%$ & $<0.001$ & $310 \mathrm{ng} / \mathrm{mL}$ & $100.0 \%$ & $83.3 \%$ \\
D1 D-dimer $\mathrm{ng} / \mathrm{mL}$ & $97.5 \%$ & $<0.001$ & $295 \mathrm{ng} / \mathrm{mL}$ & $100.0 \%$ & $83.3 \%$
\end{tabular}

Table 5: Relation between admission D0 and D1 (24 hours postadmission) D-dimer and prognosis (complicated or not complicated outcome)

\begin{tabular}{lll}
\hline & $\begin{array}{l}\text { DOD-dimer } n g / m L \\
(\text { mean } \pm S D)\end{array}$ & $\begin{array}{l}\text { D1 D-dimer } n g / m L \\
(\text { mean } \pm S D)\end{array}$ \\
\hline Not complicated & $262.00 \pm 63.62$ & $249.62 \pm 55.99$ \\
Complicated & $457.06 \pm 57.34$ & $484.12 \pm 51.76$ \\
$p$ value & $<0.001$ & 0.001 \\
\hline
\end{tabular}

${ }^{*} p$ value is significant if $<0.05$

D0 D-D with cutoff level $440 \mathrm{ng} / \mathrm{mL}$ can predict embolic stroke origin with $75 \%$ sensitivity and $90.9 \%$ specificity. D1 with cutoff level $445 \mathrm{ng} / \mathrm{mL}$ can predict embolic stroke origin with $87.5 \%$ sensitivity and $72.7 \%$ specificity (Fig. 3, Table 8 ).

\section{Discussion}

Fifteen million people suffer stroke worldwide each year as reported by the World Health Organization. Of these, 5 million die, while another 5 million are left with permanent disability. ${ }^{15}$

A biomarker panel incorporating $D-D$, brain natriuretic peptide (BNP), protein S100 beta, and matrix metalloproteinase 9 (MMP-9), in combination with non-contrast CT brain, showed considerably greater sensitivity than CT alone possesses. ${ }^{16}$

Our study was applied on 40 subjects divided into 30 patients with first-ever acute cerebrovascular stroke admitted to the ICU within 24 hours of the onset of symptoms, and 10 healthy controls. 


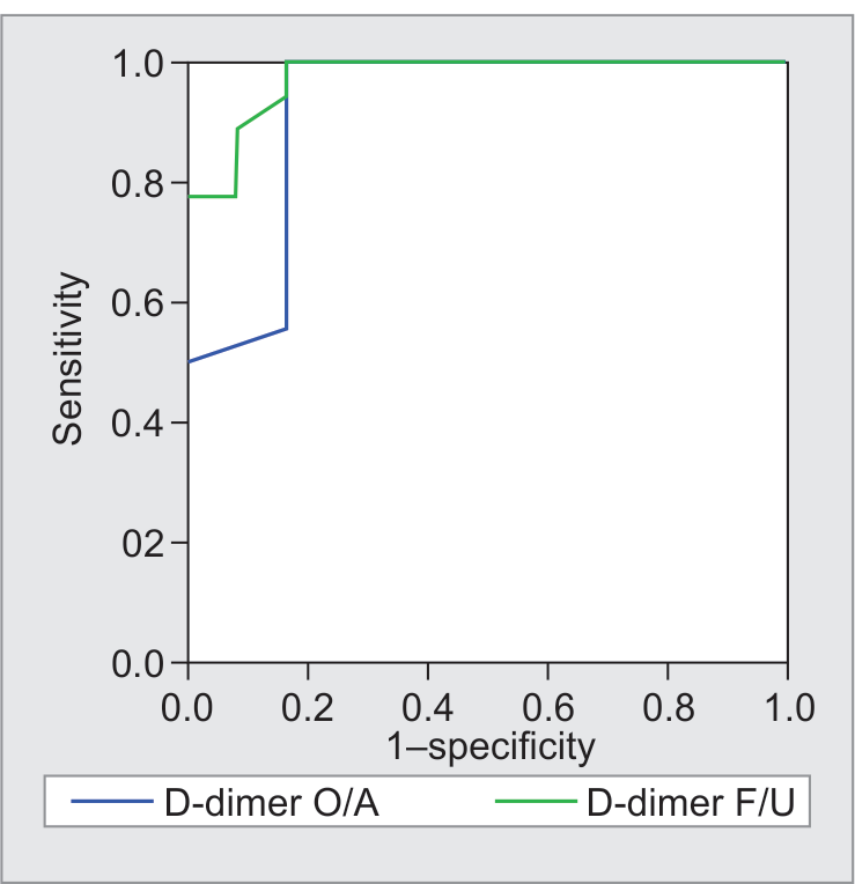

Fig. 1: ROC curve for prediction of ischemic infarct size greater than $1.5 \mathrm{~cm}$ in diffusion-weighted MRI

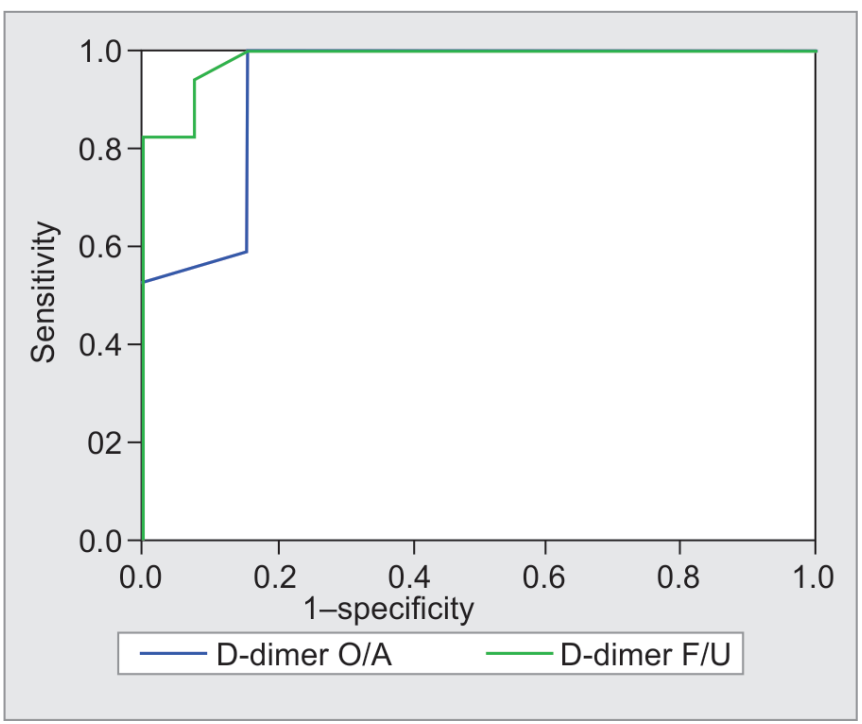

Fig. 2: ROC curve to provide the cutoff levels of admission D0 and D1 D-dimer to predict mortality in critically ill acute ischemic stroke patients

Table 6: Sensitivity and specificity of D0 (admission) D-dimer and D1 (after 24 hours) D-dimer for predicting complicated outcome

\begin{tabular}{llllll}
\hline $\begin{array}{l}\text { Complicated } \\
\text { course }\end{array}$ & AUC & $p$ & Cutoff & Sensitivity & Specificity \\
\hline D0 D-dimer & $93.2 \%$ & $<0.001$ & $350 \mathrm{ng} / \mathrm{mL}$ & $100.0 \%$ & $84.6 \%$ \\
D1 D-dimer & $98.4 \%$ & $<0.001$ & $370 \mathrm{ng} / \mathrm{mL}$ & $100.0 \%$ & $84.6 \%$ \\
\hline
\end{tabular}

Patient group included 10 males (33.3\%) and 20 females (66.7\%). The age of the patients was $52.37 \pm 8.44$ years.

In our study, comparison of mean D0 D-D between patient group and control group showed $372.53 \pm 114.69 \mathrm{ng} / \mathrm{mL}$ in patient

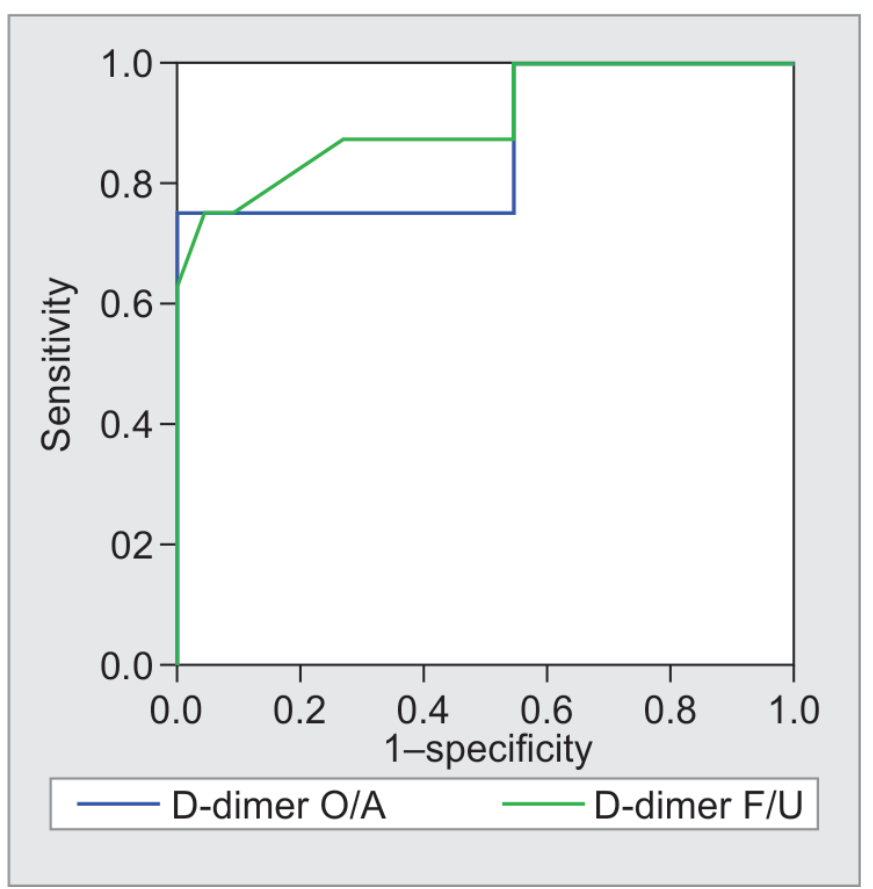

Fig. 3: ROC curve for prediction of cardioembolic origin of ischemic stroke in critically ill acute ischemic stroke patients

Table 7: Correlation between D0 (admission) D-dimer and D1 (after 24 hours) D-dimer and APACHE II score and NIHSS.

\begin{tabular}{lccc}
\hline & & D0 D-dimer & D1 D-dimer \\
\hline NIHSS & $\mathrm{R}$ & 0.768 & 0.852 \\
& $p$ & $<0.001$ & $<0.001$ \\
APACHE score & $\mathrm{N}$ & 30 & 30 \\
& $\mathrm{R}$ & 0.693 & 0.712 \\
& $p$ & $<0.001$ & $<0.001$ \\
& $\mathrm{~N}$ & 30 & 30 \\
\hline
\end{tabular}

${ }^{*} p$ value is of statistical significance if $<0.05$.

Table 8: Sensitivity and specificity of D0 (admission) D-dimer and D1 (after 24 hours) D-dimer for predicting embolic stroke

\begin{tabular}{llllll}
\hline Embolic stroke & AUC & $p$ & Cutoff & Sensitivity & Specificity \\
\hline D0- D-dimer & $86.4 \%$ & 0.003 & $440 \mathrm{ng} / \mathrm{mL}$ & $75.0 \%$ & $90.9 \%$ \\
D1 D-dimer & $90.6 \%$ & 0.001 & $445 \mathrm{ng} / \mathrm{mL}$ & $87.5 \%$ & $72.7 \%$ \\
\hline
\end{tabular}

group and $142 \pm 17.81 \mathrm{ng} / \mathrm{mL}$ in control group with statistically significant difference $(p<0.05)$.

In our study, mean D0 was significantly higher in patients than controls $(p<0.05)$.

This is in agreement with Gurkan et al. ${ }^{17}$; he included patients with AIS in 24 hours and measured their plasma D-D levels twice firstly in 24 hours and the second between 8 and 10 days. They found that the level of D-D in ischemic stroke patients in the early period is higher compared to healthy controls. The same was found by $\mathrm{Zi}$ and Shuai, $^{18}$ who reported that median D-D plasma levels were significantly higher in 240 Chinese AIS patients compared to controls. 
In our study, mean value of admission Day 0 and Day 1 D-D correlated with diffusion-weighted MRI as shown: The mean of D0 $D$-D was $450.00 \pm 63.18 \mathrm{ng} / \mathrm{mL}$ in patients with MRI positive finding $(>1.5 \mathrm{~cm})$ and $256.33 \pm 62.93 \mathrm{ng} / \mathrm{mL}$ in patients with MRI negative finding $(<1.5 \mathrm{~cm})$. The mean of D1 D-D was $475.56 \pm 61.97 \mathrm{ng} / \mathrm{mL}$ in patients with MRI positive finding $(>1.5 \mathrm{~cm})$ and $242.92 \pm 52.76 \mathrm{ng} /$ $\mathrm{mL}$ in patients with MRI negative finding $(<1.5 \mathrm{~cm})$.

Mean D0 and mean D1 D-D were significantly higher in cases with positive MRI result ( $>1.5 \mathrm{~cm}$ infarct size) than patients with MRI infarct size $<1.5 \mathrm{~cm}$ ( $p$-value $<0.05)$.

This result is in agreement with Park et al. ${ }^{4}$ They investigated the D-D levels of 59 AIS patients twice upon admission and then after 7 days. They found that the D-D level has a positive correlation with infarction volume and can be used to predict infarction volume.

Also, our study is in agreement with Matsumoto et al. ${ }^{19}$ They identified 124 AIS patients with non-valvular AF (NVAF) admitted within 48 hours of symptom onset. Infarction volume measured from CT taken after $3 \pm 1$ days from the onset significantly correlated with admission D-D level.

Also, our study is in agreement with $\mathrm{Zi}$ and Shuai, ${ }^{18}$ who concluded that $D$-D levels increased with increasing infarct volume.

However, our study is not in agreement with Knauer et al. ${ }^{20}$ They investigated hospitalized AIS patients. Patients underwent MRI within 6 hours from symptom onset. We measured D-D by ELISA, the reference standards for D-D assays ${ }^{21}$, while they measured by sandwich immunofluorescence laboratory assay. They found that the correlation between the biomarker like D-D (measured only once) and DWI lesion volume was poor. They recommended against the employment of D-D as it has no diagnostic validity and might cause unjustified time delay.

In the present study, the relation between D0 and D1 and prognosis and mortality of studied patients showed statistical significance between D0 and D1 D-D and complex course chest infection and/or mortality ( $p$-value $<0.05$ ).

This is in agreement with Feinberg et al., ${ }^{22}$ who measured D-D in 70 patients within 1 week of stroke and reported that D-D is significantly correlated with mortality. This association appears to be independent of stroke severity or stroke type.

This is in agreement also with Ustundag et al., ${ }^{23}$ who measured the serum D-D of 91 AIS patients in the first 24 hours after stroke symptoms started. There was a statistically significant correlation between D-D levels and mortality as well as neurological disability.

Also, Yang et al. ${ }^{5}$ concluded that D-D levels are useful biomarkers to predict outcome and 90-day mortality after AIS.

In our study, there was a statistically significant correlation between D0 and D1 D-D and APACHE score and NIHSS ( $p$-value $<0.05)$.

This is in agreement with $\mathrm{Zi}^{18}{ }^{18}$ who found that D-D levels increased with increasing severity of stroke as defined by the NIHSS.

Also, this is in accord with Yang et al., ${ }^{5}$ who found a direct correlation between D-D concentrations and NIHSS in 220 AIS patients within the ED.

In our study, the mean NIHSS of patients was $8.37 \pm 4.44$, and also, the mean APACHE score was $12.47 \pm 3.88$.

Comparison of D0 and D1 mean levels between patients with and without risk factors of stroke showed the presence of statistical significance only between patients with and without AF and IHD.

This is in agreement with Ageno et al., ${ }^{24}$ who studied 126 hospitalized AIS patients and underwent D-D assay on days 1, $6 \pm 1$, and $12 \pm 1$. They found that at all three measurements, D-D levels were significantly higher within the cardioembolic group than within the atherothrombotic and lacunar groups.

Also, Koch et al. ${ }^{25}$ studied 59 patients within 24 hours of AIS with different stroke subtypes and revealed that patients with cardioembolic stroke had significantly higher D-D concentration than controls.

Also, our study is in agreement with Yuan, ${ }^{26}$ who studied 300 hospitalized AIS patients admitted within 7 days of symptom onset. D-D levels were detected within 24 hours of admission. Patients with cardioembolism had the top D-D levels; the difference was statistically significant among the five TOAST criteria subtypes, while the lacunar stroke patients had the lowest level of D-D. However, Gurkan et al. ${ }^{17}$ stated that D-D levels are not significantly higher in the atrial fibrillation and cardioembolic stroke patients compared with other groups. Also, Krarup et al. ${ }^{27}$ showed that $D-D$ and other markers of coagulation are not connected to clinical stroke progression in cardioembolic stroke; yet, they also performed D-D (enzyme immunoassay) not ELISA and they tested it once and did not correlate the levels with DW-MRI imaging.

Also, Matsumoto et al. ${ }^{19}$ reported that D-D levels upon admission in 124 AIS patients are significantly related to functional outcome after cardioembolic stroke in NVAF patients. Also, Yuan and $\mathrm{Shi}^{26}$ studied hospitalized 300 AIS patients within 7 days of symptom onset. In all patients, the plasma D-D levels were detected within 24 hours of admission.

\section{Conclusion}

The plasma D-D assay can be a simple reliable readily accessible emergency biomarker.

D-D levels are significantly higher in AIS patients compared to healthy controls. D-D level is correlated with the infarction size in MRI, APACHE II score, and NIHSS. D-D can be considered as an inexpensive non-invasive valuable marker for predicting infarction size by diffusion-weighted MRI $(>1.5 \mathrm{~cm})$, cardioembolic origin of stroke, and prognosis. We suggest additional studies to investigate the additive role of $D-D$ to imaging studies and other biomarkers panel.

\section{Limitations}

The relatively small sample size is due to the cost and difficulty of MRI procedure, which is not a routine investigation in acute stroke patients ineligible for thrombolysis. The small sample size of the patients and healthy controls may have affected the statistical validity of results. A larger sample size is recommended in the coming research.

$D-D$ levels were performed twice. More frequent follow-up could be more beneficial to yield data concerning how long D-D become elevated after the commencement of clot formation or for how long $D-D$ level remains increased in circulation.

No follow-up of D-D and long-term morbidity and mortality after ICU discharge.

False-positive D-D levels can occur in different cases like hepatic diseases, inflammatory conditions, high rheumatoid factor, malignancy, trauma, pregnancy, recent operation as well as in geriatric population. ${ }^{28}$ Additionally, false-negative results can occur either if the blood sample is taken prematurely after clot formation or if the test is deferred for some days. Dabigatran and rivaroxaban anticoagulant medications decrease $D-D$ concentrations but do not 
intervene with the D-D assay. ${ }^{29}$ Yet, in our study, we include only the first-ever stroke without prior use of anticoagulation.

\section{Ethical approval}

An informed consent is obtained from all patients or their caregivers. All ethical standards were followed.

\section{ORCID}

Nora I Abbas @ https://orcid/org/0000-0003-0513-4561

\section{References}

1. Mozaffarian D, Benjamin EJ, Go AS, Donna K. Arnet, M.J Blaha, et al. Heart disease and stroke statistics - 2015 update: a report from the American Heart Association. Circulation 2015 Jan 27;131(4):e29-e322. DOI: 10.1161/CIR.0000000000000152.

2. Whiteley W, Chong W, Sengupta A, Sandercock P. Blood markers for the prognosis of ischemic stroke: a systematic review. Stroke 2009;40(5):380-389. DOI: 10.1161/STROKEAHA.108.528752.

3. Meng R, Wang X, Hussain M, Dornbos D III, Meng L, Liu Y, et al. Evaluation of plasma D-dimer plus fibrinogen in predicting acute CVST. Int J Stroke 2014 Feb;9(2):166-173. DOI: 10.1111/ijs.12034.

4. Park YW, Koh EJ, Choi HY. Correlation between serum D-dimer level and volume in acute ischemic stroke. J Korean Neurosurg Soc 2011;50(2):89-94. DOI: 10.3340/jkns.2011.50.2.89.

5. Yang XY, Gao S, Ding J, Chen Y, Zhou XS, Wang JE. Plasma D-dimer predicts short term poor outcome after acute ischemic stroke. PLoS One 2014 Feb 24;9(2):e89756. DOI: 10.1371/journal.pone.0089756.

6. Goldenberg NA, Jenkins S, Jack J, Armstrong-Wells J, Fenton LZ, Stence NV, et al. Arteriopathy, D-dimer, and risk of poor neurologic outcome in childhood onset arterial ischemic stroke. J Pediatr 2013;162(5):1041-1046. DOI: 10.1016/j.jpeds.2012.11.035.

7. Školoudík $D, B a r M$, Šaňák $D$ et al. D-dimers increase in acute ischemic stroke patients with the large artery occlusion, but do not depend on the time of artery recanalization. J Thromb Thrombolysis 2010;29:477-482. DOI: https://doi.org/10.1007/s11239-009-0372-9.

8. Berge $E$, Friis $P$, Sandset P. Hemostatic activation in acute ischemic stroke. Thromb Res 2001 Jan 15;101(2):13-21. DOI: 10.1016/s00493848(00)00380-7.

9. Delgado P, Alvarez-Sabin J, Abilleira S, Santamarina E, Purroy F., Arenillas JF, et al. Plasma D-dimer predicts poor outcome after acute intracerebral hemorrhage. Neurology 2006;67(1):94-98. DOl: 10.1212/01.wnl.0000223349.97278.e0.

10. Righini M, Goehring C, Bounameaux $H$, Perrier A. Effects of age on the performance of common diagnostic tests for pulmonary embolism. Am J Med 2000;109(5):357-361. DOI: 10.1016/S0002-9343(00)00493-9.

11. Isenegger J, Meier N, Lammle B, Isenegger J, Meier N, Lämmle B, et al. $D$-Dimers predict stroke subtype when assessed early. Cerebrovasc Dis 2010;29(1):82-86. DOI: 10.1159/000256652.

12. Abdel Ghani AAM, Zaitoun AM, Gawish $\mathrm{HaH}, \mathrm{AboWarda} M \mathrm{MH}$. Prognostic value of $D$-dimer in diffusion weighted-MRI defined early ischemic stroke recurrence. Egypt J Neurol Psychiat Neurosurg 2011;48(3):215-222. DOI: 10.4103/1110-1083.192656. The article is available from available from: http://www.ejnpn.eg.net/text. asp?2016/53/3/146/193090.

13. Schlegel D, Kolb S, Luciano J, Tovar JM, Cucchiara BL, Liebeskind DS, et al. Utility of the NIH Stroke Scale as a predictor of hospital disposition. Stroke 2003;34(1):134-137. DOI: 10.1161/01.str.0000048217.44714.02.

14. Adams HP Jr, Bendixen BH, Kappelle LJ, Biller J, Love BB, Gordon DL, et al. Classification of subtype of acute ischemic stroke. Definitions for use in a multicenter clinical trial. TOAST. Trial of Org 10172 in acute stroke treatment. Stroke 1993 Jan;24(1):35-41. DOI: 10.1161/01. str.24.1.35.

15. Mackay J, Mensah GA. The atlas of heart disease and stroke. In: Global burden of stroke. World Health Organization and Center for Disease Control and Prevention; 2004. Available from: http://www.who.int/ cardiovascular_diseases/resources/atlas/en.

16. Laskowitz D, Blessing R, Floyd J, White WD, Lynch JR. Panel of biomarkers predicts stroke. Ann NY Acad Sci 2005;1053:30. DOI: 10.1196/annals.1344.051.

17. Gurkan ZM, Orken DN, Tekan UY, Çelebi LG, Tak AZ, et al. D-Dimer levels in etiological diagnosis of ischemic stroke and relationship the prognosis. SETB 2013;47(1):1-4. DOI: 10.5350/SEMB2013470101.

18. Zi WJ, Shuai J. Plasma D dimer levels are associated with stroke subtypes and infarction volume in patients with acute stroke. PLoS One 2014;9(1):e86465. DOI: 10.1371/journal.pone.0086465. PMCID: PMC3896474.

19. Matsumoto M, Sakaguchi M, Okazaki S, Furukado S, Tagaya M, Etani $\mathrm{H}$, et al. Relationship between plasma D-dimer levels and cerebral infarction volume in patients with non-valvular AF. Cerebrovasc Dis 2013;35(1):64-72. DOI: 10.1159/000345336.

20. Knauer C, Knauer K, Muller S, Ludolph AC, Bengel D, Müller HP, et al. A biochemical marker panel in MRI-proven hyper acute ischemic stroke-a prospective study. BMC Neurol 2012 Mar 8;12:14. DOI: 10.1186/1471-2377-12-14.

21. Linkins LA, Lapner ST. Review of D-dimer testing: good, bad, and ugly. Int J Lab Hematol 2017 May;39(Suppl. 1):98-103. DOI: 10.1111/ ijlh.12665.

22. Feinberg WM, Erickson LP, Bruck D, Kittelson J. Hemostatic markers in acute ischemic stroke: association with stroke type, severity and outcome. Stroke 1996;27:1296-1300. DOI: 10.1161/01.STR.27.8.1296.

23. Ustundag M, Orak M, Guloglu C, Tamam Y, Sayhan MB. Plasma D-dimer levels in acute ischemic stroke: association with mortality, stroke type and prognosis. Nobel Med 2010;6(2):37-42. The article is available from Available from: https://www.nobelmedicus.com/en/ Article.aspx?m=196.

24. Ageno W, Finazzi S, Steidl L, Biotti MG, Mera V, Melzi D'Eril G, et al. Plasma measurement of D-dimer levels for the early diagnosis of ischemic stroke subtypes. Arch Intern Med 2002 Dec 9-23;162(22):2589-2593. DOI: 10.1001/archinte.162.22.2589.

25. Koch HJ, Horn M, Bogdahn U, Ickenstein GW. The relationship between plasma $\mathrm{D}$-dimer concentrations and acute ischemic stroke subtypes. J Stroke Cerebrovasc Dis 2005; 14: 75-79. DOI: 10.1016/j. jstrokecerebrovasdis.2004.12.002.

26. Yuan W, Shi ZH. The relationship between plasma D-dimer levels and outcome of Chinese acute ischemic stroke patients in different stroke subtypes. J Neural Transm (Vienna) 2014 Apr;121(4):409-413. DOI: 10.1007/s00702-013-1113-y.

27. Krarup LH, Sandset EC, Sandset PM, Berge E. D-Dimer levels and stroke progression in patients with acute ischemic stroke and atrial fibrillation. Acta Neurol Scand 2011 Jul;124(1):40-44. DOI: 10.1111/j.1600-0404.2010.01409.x.

28. Kabrhel C, Mark Courtney D, Camargo CA, Plewa MC, Nordenholz KE, Moore $\mathrm{CL}$, et al. Factors associated with positive $\mathrm{D}$-dimer results in patients evaluated for pulmonary embolism. Acad Emerg Med 2010;17(6):589-597. DOI: 10.1111/j.1553-2712.2010.00765.x. PMC: 3538031. PMID: 20624138.

29. Baglin T, Keeling D, Kitchen S. Effects on routine coagulation screens and assessment of anticoagulant intensity in patients taking oral dabigatran or rivaroxaban: guidance from the British Committee for Standards in Haematology. Br J Haematol 2012 November;159(4):427-429. DOI: 10.1111/bjh.12052. PMID: 22970737. 